\title{
El suicidio como performance en la obra póstuma de José María Arguedas
}

El escritor José María Arguedas fue duramente cuestionado durante su vida sobre la autenticidad de sus representaciones de la realidad andina. Tras su suicidio en 1969, se publicó El zorro de arriba y el zorro de abajo, novela permeada por la muerte que acecha a los personajes, construida como una sucesión de escenas-discursos que este artículo contempla como actos performativos. Se sugiere que el suicido de Arguedas, dada su teatralidad, constituye una performance que se proyecta sobre la novela a partir de los diarios del escritor, operando como elemento de veridicción que refuerza la posibilidad del autor de representar fidedignamente la realidad andina. El prisma de la performatividad permite una exploración de las conexiones entre verdad, trascendencia y suicidio en la obra póstuma de Arguedas.

Palabras claves: suicidio, performance, cosmovisión andina, discursosescenas, polifonía, José María Arguedas

Peruvian writer José María Arguedas' claim of representing Andean reality in his literary work was challenged during his life. After his suicide in 1969, his last novel El zorro de arriba y el zorro de abajo was published. The story, in which death constantly threatens the characters, is built on a series of "scene-discourses" contemplated in this article as performative acts. Likewise, this work suggests that the novelist's suicide can be considered an act of performance as well, which is projected into the fictional work, and operates as an element of veridiction, reaffirming the author's identity as an authentic representative of Andean reality. Through the lens of performativity, it is possible to explore the connections between truth, trascendence and suicide inscribed in the last work of Arguedas.

Keywords: suicide, performance, Andean cosmovision, discourse-scenes, polyphony, José María Arguedas

La obra del autor indigenista peruano José María Arguedas, antropólogo, novelista, poeta, cuentista y traductor de textos quechuas al español, es ampliamente conocida por su vastedad y diversidad, y en particular por la 
exploración y recreación del mundo andino. Como se sabe, a pesar de su notoriedad a nivel nacional y latinoamericano, la escritura de Arguedas fue muchas veces cuestionada por reconocidos autores y estudiosos de la literatura y las ciencias sociales, tanto desde la perspectiva del lenguaje utilizado - que no se acercaba, según ciertos críticos, a la técnica de los protagonistas del boom latinoamericano - como a partir del punto de vista de una falta de autenticidad en la representación de la realidad andina. ${ }^{\mathrm{I}} \mathrm{A}$ tales manifestaciones el escritor contestó amargamente argumentando su posibilidad de representar fidedignamente al sujeto de los Andes, tanto en la recreación de su mundo como en la reproducción de sus formas de expresión, debido a su experiencia vivencial en los Andes. ${ }^{2}$ A partir de 1973 - cuatro años después de su suicidio en 1969 - se dio inicio a una revalorización de la narrativa de Arguedas incorporándose nuevas perspectivas, las más de las cuales hacían hincapié en su novela póstuma $E l$ zorro de arriba y el zorro de abajo, publicada por primera vez en 1971. ${ }^{3}$ Uno de los académicos más lúcidos de esta nueva crítica, Antonio Cornejo Polar, señaló otras rutas de interpretación para la última novela de Arguedas, en particular con referencia al inacabamiento que se imputaba al texto: "Lo no escrito resulta ser una dimensión de sentido de El zorro no la de menor importancia: allí reside la significación de la muerte y de la realidad indecible. La tragedia radical que ocupa en la estructura de la novela el estrato de "la existencia trascendente"' (Los universos narrativos 264). La novedosa visión rescataba tanto la escritura como la significación de la obra. Y en efecto, como lo sugería el crítico, el rol principal de la muerte es palpable en El zorro, novela en la que la realidad representada se encuentra permeada por la aniquilación física y moral que acecha constantemente a los personajes. La relevancia de la muerte se hace aún más evidente si se considera que la obra ficcional se intercala - tanto durante el proceso escritural como en su posterior publicación - con los diarios y cartas del autor, en los que su inminente suicidio es registrado desde el inicio como un tema urgente. Fue el propio Arguedas quien, en el "Primer Diario," alertaba sobre las posibles implicancias de la muerte por suceder:

Es maravillosamente inquietante esta preocupación mía, y de muchos, por arreglar el suicidio de modo que ocurra de la mejor forma posible ... Voy a tratar, pues, de mezclar, si puedo, este tema que es el único cuya esencia vivo y siento como para poder transmitirlo a un lector; voy a tratar de mezclarlo y enlazarlo con los motivos elegidos para una novela que, finalmente, decidí bautizarla: "El zorro de arriba y el zorro de abajo" ... también lo mezclaré con todo lo que en tantísimos instantes medité sobre la gente y sobre el Perú. (I2) 
El suicidio se muestra, paradójicamente, como impulso vital, de cuya fuerza resulta la "mezcla" a la que Arguedas hace referencia. Dicha mezcla se constituye en acto creativo - la escritura - desde el que se piensa, recrea y organiza la muerte. La "mezcla" a la que alude Arguedas no se limita entonces a la inscripción de la intención de suicidio en los diarios, sino que transita hacia y se asienta en los motivos de su última ficción. Esto resulta particularmente sugerente en tanto se trata de un autor suicida que configura un lector para un texto que sabe va a sobrevivirlo. En este artículo abordo el complejo entramado textual que enlaza lo ficcional, lo autobiográfico y lo real, a partir de la consideración del suicidio como performance y sus proyecciones en la obra póstuma, la cual plantea a su vez diversos niveles performativos. ${ }^{4}$ La mirada hacia la performatividad del último trabajo del autor indigenista permite aquilatar las formas en que El zorro desafía las convenciones genéricas mostrando su clara perspectiva andina, y revelando certeros vínculos entre muerte, escritura, verdad y trascendencia.

Sobre el suicidio de Arguedas se han tejido diversas teorías que aparecen en innumerables libros y artículos, desde aquellas interpretaciones que priorizan su depresión clínica y su niñez solitaria y atormentada, hasta las que subrayan la imposibilidad de soportar el acabamiento del mundo andino tal como él lo concebía y lo había vivido. ${ }^{5}$ Por otro lado, la simultaneidad y complementariedad de la novela y los diarios no han sido siempre bien comprendidas. Por ejemplo, el crítico Tulio Mora vio El zorro como un simple testimonio de los conflictos interiores del autor (Cornejo Polar, Los universos 264); la obra también ha sido considerada como una novela frustrada en la que a Arguedas le había resultado imposible plasmar la realidad conflictiva que intentaba representar; una narración interrumpida por la disrupción continua del diario personal (Franco 5). Sin embargo, aunque el propio autor mencionó repetidamente el "truncamiento" de su novela final, lo hizo en un sentido marcadamente distinto: para él, la obra contenía "el germen de otra más vasta" (Arguedas, El zorro 289) y su cuerpo, aunque deforme, era "capaz de andar" (290). Con estas palabras Arguedas otorgaba a su último trabajo literario la oportunidad de ir más allá de las fronteras de lo estrictamente representado, la facultad de trascender los límites de la escritura y, en su caso particular, de la vida misma.

Ahondando en los vínculos entre la obra ficcional y la factual, es importante reparar en el pensamiento suicida que de manera creciente va acompañando el proceso de escritura. Los diarios - de los que algunas secciones son publicadas de manera anticipada en revistas académicas - 
muestran las disquisiciones de Arguedas sobre los diferentes métodos para suicidarse, sus motivaciones, el lugar previsto (la Universidad Agraria) y el efecto que el hallazgo de su cuerpo pudiera causar. ${ }^{6} \mathrm{La}$ decisión de Arguedas de hacer públicas sus preocupaciones antes de suicidarse pone en evidencia la aguda conciencia del autor sobre el posible impacto de su muerte. Adicionalmente, puede leerse la correspondencia publicada junto a la novela, que incluye detalladas disposiciones sobre el montaje del funeral (lugar, ceremonia, discursos, música): "después de que algún hermano mío tocara charango o quena ... [que hable] A nombre de la Universidad, si es posible y él acepta, Alberto Escobar ... Me gustan, hermanos, las ceremonias honradas, no las fantochadas del carajo" (285286). ${ }^{7}$ Dada la minuciosidad y anticipación con la que se da forma al suicidio y a la ceremonia subsecuente, es imprescindible detenerse en la teatralización que se infunde al acto final, que sugiere el carácter performativo de una muerte por mano propia que se anuncia con antelación y se ejecuta en un recinto público, así como de un funeral planificado al detalle para la posteridad. Desde esta perspectiva, es posible considerar el suicidio de Arguedas como un acto de performance tanto en el sentido de la capacidad para llevar a cabo efectivamente una acción, como en relación a la puesta en escena que se origina en esta acción y que incluye un escenario (la universidad), actores (músicos, oradores) y una audiencia prevista (asistentes al funeral). ${ }^{8}$

La consideración del suicidio de Arguedas como performance, aunada a las conexiones entre los diarios, correspondencia y novela, en particular con referencia a la inclusión de la muerte, abre un espacio para el análisis textual de El zorro, en el que la relación entre verdad y suicidio resulta relevante. Sobre este tema, Michel Braud ha señalado que la palabra de un autor suicida aclara de manera retrospectiva la experiencia que se narra, modificando de esta manera la recepción y confiriendo una nueva irrecusabilidad a la obra, revelando como verdadera tanto la aventura existencial como la escritura (36). En este sentido, para una mejor apreciación de los vínculos entre verdad, escritura y suicidio con respecto a la obra que nos atañe, vale la pena recordar la persistente defensa esgrimida por Arguedas de la validez de sus representaciones ficcionales de lo andino, que se puede vincular con una sensación de aislamiento con respecto a otros autores consagrados, lo que se manifiesta en sus diarios paralelamente a la reafirmación del sujeto de la enunciación como portador y transmisor de los elementos de la identidad andina:

... este Cortázar que aguijonea con su genialidad, con sus solemnes convicciones de que mejor se entiende de la esencia de lo nacional desde las altas esferas de lo 
supranacional. Como si yo, criado entre la gente de don Felipe Maywa, metido en el oqllo mismo de los indios durante algunos años de la infancia para luego volver a la esfera "supraindia" de donde había "descendido" entre los quechuas, dijera que mejor, mucho más esencialmente interpreto el espíritu, el apetito de don Felipe, que el propio don Felipe. (Arguedas, El zorro 19-20)

La imposibilidad de comprender "lo esencial" - y a partir de ello, la alusión implícita a una representación no válida - se traslada a los escritores protagonistas del boom latinoamericano. En un pronunciamiento de falsa modestia, Arguedas se confiesa incapaz de arrogarse el derecho a interpretar el espíritu del sujeto andino al afirmar que nadie puede representar mejor a Felipe Maywa que el propio Maywa. Esta afirmación, que aparentemente anula todo intento de representación fidedigna, al mismo tiempo acerca a Arguedas a esta posibilidad, puesto que inmediatamente después el autor se sitúa en el meollo del espacio andino, un lugar al que tiene el privilegio de aproximarse mejor que cualquier otro escritor latinoamericano, ya que él - y no otros - es quien ha "descendido" entre los indios. Este reclamo de identificación - reclamo legítimo considerando que, como bien lo prueba Martin Lienhard en Cultura andina y forma novelesca, la obra de Arguedas incluye en su polifonía la oralidad y expresión cultural andina y popular - está presente a lo largo del diario y sitúa la obra literaria de Arguedas en el campo de la verdad, entendida desde una dimensión literaria y no ontológica. Puesto que el autor se autoconstruye como persona capaz de percibir las cosas al modo andino como el lenguaje del nionema, el sol y las cascadas, que "retratan el mundo para los que sabemos cantar en quechua" (Arguedas, El zorro 13) - hace suya la habilidad para representarlo. La escritura del diario, situada temporalmente entre el intento del suicidio del pasado y el inminente suicidio del futuro, se dota a sí misma de la irrecusabilidad que menciona Braud, convirtiéndose en instrumento de "veridicción" a través del cual el escritor se legitima a sí mismo como portador e intérprete de lo andino, validando lo narrado en los diarios y el texto literario del que estos forman parte, y desplazando finalmente esta validez a la totalidad de su vida y su obra. ${ }^{\text {IO }}$ Como afirma José Alberto Portugal, el suicidio de Arguedas "no puede ser visto como un acto aislado de otros actos o gestos simbólicos del sujeto, pues se trata de un hecho indeleblemente inscrito por y en su literatura" (479). El trágico final del autor se constituye entonces en clave principal de lectura de la última obra arguediana. El suicidio como acto performativo que reclama una verdad y trascendencia para la posteridad, enlaza la escritura de los diarios, la novela y las cartas a través de la incorporación de la muerte, en un juego intertextual que vincula el espacio 
de la realidad, donde se ejecuta el suicidio, y el de la escritura, sobre el que se proyecta el acto final.

A diferencia de su narrativa anterior que casi en su totalidad tiene como referente escenarios de los Andes del Perú, El zorro se enmarca, a nivel espacial y temporal, en Chimbote, puerto de la costa peruana que durante el período del "boom de la anchoveta" fue un motor que impulsó la economía capitalista de la región en los años cincuenta y sesenta, convirtiendo el país en una potencia pesquera. ${ }^{\text {II }}$ La novela narra la convivencia conflictiva entre los migrantes provenientes de las serranías peruanas que llegaban a Chimbote en busca de sustento a través de la pesca y un conglomerado humano de distintos orígenes, compuesto por migrantes andinos, y también por sujetos mestizos, criollos y foráneos e inmigrantes de distintas nacionalidades y etnias. Desde el inicio, el relato invita a recorrer espacios de caos, como el burdel, el mercado, y el mar como medio conflictivo de extracción y supervivencia. En el marco de la explotación de la anchoveta, la economía de Chimbote se representa como un sistema regido corrupta y despóticamente por los dirigentes de las compañías pesqueras, quienes organizan una red de cantinas y burdeles a los que el asalariado de la pesca acude presuroso, de manera que tanto su labor como su consumo redundan en el enriquecimiento de los empresarios. Se trata de una sociedad en la que prima el dinero, como objeto de deseo que provee al individuo de bienes temporales y simultáneamente lo corrompe. La sociedad es víctima de la degradación moral impuesta por la economía del puerto, que lo transforma rápidamente en un espacio deshumanizante, "un hormiguero de hombres que creo podrían representar a todas las escalas de la humanidad en alfabetismo y todo cuanto hay" (Arguedas cit. en 0' Hara 57). De este caos emerge una nueva visión de Arguedas sobre el Perú, tal como confiesa en I967 a Alejandro Ortiz, cuando lo pone al tanto de su escritura: "creo haber enlazado todas esas historias dispersas, formidables, a mí me parece, quizá se pueda mostrar el Perú de hoy que es formidable, tan mezclado, tan hirviente, tan caótico aparentemente" (Ortiz 25I). En este sentido, la labor comunicativa de Arguedas puede explicarse a través de la noción de "trabajador cultural" de Mabel Moraña: "un productor cuya práctica superestructural se nutría del contacto directo con los materiales y espacios de producción simbólica y se definía como solidaridad con los sectores populares" (I62). La elección de este contexto, un microcosmos en el que un capitalismo exacerbado violenta todos los estratos sociales, procede, pues, de la vocación de Arguedas de trabajar de manera cercana con los sectores populares de origen andino. Por otro lado, está también presente el deseo de impregnar la novela de su propia persona: "la novela 
para ser tal tiene que ser el reflejo de lo que soy yo y a través mío, si es posible, el reflejo de Chimbote: de ese inaprensible hervidero humano y a través de ese hervidero, mi propio hervidero" (Murra y López Baralt I8II82). Realidad y ficción se ven así imbricadas en una obra que construye un mundo delirante y agónico.

Los personajes descritos en El zorro son tan caóticos como su entorno: el andino Esteban de la Cruz lucha por sobrevivir, ya que ha contraído una afección grave durante su trabajo en las minas, que lo obliga a vomitar carbón de manera continua. ${ }^{\mathrm{I} 2}$ El "mudo" abriga el perturbador deseo de asesinar al "gringo" Maxwell. El "zambo" Moncada recorre erráticamente las calles de Chimbote pronunciando discursos sobre verdad y muerte, y guía a los pobladores andinos hacia el cementerio, de donde los ricos han desterrado a los pobres. Y como si no bastara con la muerte que ronda la obra, hay que señalar los desenlaces que no fueron incluidos en el texto, pero sí se hallaban en el plan inicial de la novela, de acuerdo a las declaraciones de Arguedas en su "¿Último Diario?": el suicidio de Orfa, el desenlace de la historia de Tinoco, el fallecimiento de Esteban de la Cruz, acompañado del discurso funerario de Moncada, y la horrenda ejecución de Maxwell, para quien estaba destinado el degollamiento (El zorro 283285). La muerte asola la obra como fantasma y también como salida única al caos imperante, en el que se ven confrontados el capitalismo que establece las condiciones de explotación de los recursos del puerto y la cosmovisión andina. El escenario costeño y marino de la novela póstuma no impide la inserción de lo andino, que emerge como canto desgarrado y muriente. Así lo corrobora Lienhard cuando menciona que en la novela cohabitan y se enfrentan diversos discursos y lenguajes que tienden a "fortalecer el aspecto indígena en todas las instancias" (Cultura andina 2I), aspecto del que Arguedas fue plenamente consciente desde sus primeras incursiones literarias, ya que, según su propia confesión, en su primer relato utilizó "un tipo de castellano que es una especie de mezcla pero de estilo, en el cual el espíritu del quechua, las características del quechua están bastante vibrantes" (Gutarra 68). Más específicamente, el propósito de El zorro habría sido "imponer a uno de los vehículos privilegiados de la cultura dominante, la novela, la presencia de esa otra cultura" (Lienhard, Cultura andina 22). Esta posición se plasmaría no como una "visión interior de lo indio", sino como "una perspectiva indígena interna a la novela" $(23)$. $^{13}$ A partir de estos densos lenguajes, los extensos discursos que constituyen la parte medular de la obra dan lugar a una narrativa visiblemente fragmentada, percibida como retazos cuyos hilvanes no siempre son evidentes para el lector. ${ }^{\mathrm{I}}$ 
Un aspecto singular de la novela son los diálogos de los zorros de arriba y abajo, que actúan como presentadores y comentadores de la historia que se narra, y que estarían incluyendo la visión de los sujetos de arriba (del ande) y los sujetos de abajo (migrantes andinos en la costa). ${ }^{15}$ Los zorros evocan figuras de origen quechua que aparecieron por vez primera en los mitos narrados en Dioses y hombres de Huarochirí, el manuscrito del siglo dieciséis traducido al español por Arguedas ${ }^{16}{ }^{16}$ tanto en ambos textos - el manuscrito colonial y la novela de Arguedas - los zorros son prototipos del cuentista oral (Lienhard, "La última novela" 19I), sus líneas constituirían una instancia de performatividad dentro de la narración. Ute Berns, quien ha sistematizado la relación entre narratología y performatividad, concibe esta última como una noción posible de aplicar a narrativas escritas. Tomada de esta manera, hace referencia a performances recreadas en un plano mental. El lector estaría reconstruyendo la dimensión performativa en su mente; se trata de una performance imaginada (96). El aspecto performativo es notorio en la construcción textual de El zorro como una cadena de escenas sucesivas, un "tipo particular de artefacto (de novelas como escenas) orientado a captar la atención (suscitarla, intensa, nueva) sobre el drama de la sociedad peruana" (Portugal 472). Los monólogos y diálogos constituyen escenas teatralizadas por sí mismas, mientras que los diálogos de los zorros de arriba y de abajo discurren en otra dimensión espacial y temporal, que evoca el mito andino del que provienen. Por otro lado, los diarios, que no pueden ser desvinculados de la novela, representan una instancia textual que da cuenta de la performatividad del suicidio. El zorro se adscribe así a distintos niveles de performatividad, en términos de Berns: "Performativity 2.I refers to actions directly presented but not mediated by a narrator ... Performativity $\mathbf{2 . 2}$ refers to the narrator's agency or the act of narration. Here performativity resides, for example, in the narrator's verbal self-thematizations, in her explicit comments on the story or the act of narration and in addresses to the reader" (96). En la novela de Arguedas se diversifican los niveles de performatividad: un nivel haría referencia a las acciones presentadas directamente y no mediadas por el narrador, como aquellas escenas que componen el relato de fondo, mientras que la intervención del narrador, que se escinde en la figura del autor y los personajes de los zorros, daría cuenta de otro nivel, conectado a la agencia del narrador, que en El zorro se expresa en los comentarios sobre la historia o sobre el acto de narrar. La incorporación de los zorros como cuentistas orales dota a la novela póstuma de una instancia narrativa distinta a la del autor y el relato central, que a su vez hace posible la intervención disimulada del autor. El conjunto de representaciones 
escenificadas produce una performatividad que resulta inherente a la obra y que desafía el género novelístico mismo, coadyuvando a una recepción distinta al enlazar en la percepción del lector discurso, voz e imagen, permitiéndole recrear las escenas de manera más vívida y posibilitando la deconstrucción de un relato fragmentado que yuxtapone visiones de culturas encontradas. ${ }^{17}$ La muerte recorre cada uno de los niveles performativos, dejando mensajes como claves que el lector debe descifrar.

Las secciones sobre los zorros enfatizan el rol programático de estas figuras, como narradores desde una perspectiva andina, "una instancia narrativa general 'quechua' que organiza el texto español a partir de un pensamiento quechua" (Lienhard, "La última novela" I89). Además, resulta sugerente su papel como agentes conectores entre las instancias autorial y ficcional, por ejemplo, cuando el zorro menciona que "El individuo que pretendió quitarse la vida y escribe este libro era de arriba" (Arguedas, El zorro 62), situando al escritor una vez más en el espacio andino. Un aspecto performativo que resulta más que evidente es el de las danzas que realizan los zorros frente a los personajes. Estas danzas tendrían un significado andino: para Gladys Marín, el baile de don Diego sugiere un regreso a elementos primordiales de la cosmovisión andina a través de una transformación de colores que van desde "el fuego y la sangre hasta lo originario y primario" y finalmente remiten a la idea de eternidad, al alcanzar el blanco de las piedras, fundadoras del mundo en la dimensión inca (La experiencia americana 244). La idea de eternidad, recurrente en la obra póstuma de Arguedas, se revela en las danzas y se irá manifestando persistentemente, como veremos, a lo largo de la novela. En relación a la perspectiva andina de la obra, las danzas conectan el mundo del relato con un universo mágico andino, y forman parte de aquellos elementos a través de los cuales el autor está "afirmando la legitimidad de esos símbolos y esas formas, está afirmando el poder y la capacidad esclarecedora de la cultura quechua, está afirmando la universalidad de la cultura quechua" (Cornejo Polar, Escobar, Lienhard y Rowe 33). Los zorros desempeñan también, como se ha mencionado, el rol de observadores y comentadores del proceso narrativo y de lo que acaece en Chimbote. Cumpliendo con dicha función, describen los elementos del contexto:

Muy fuertemente aquí, los olores repugnantes y las fragancias; las que salen del cuerpo de los hombres tan diferentes, de aguas hondas que no conocíamos, del mar apestado, de los incontables tubos que se descargan unos sobre otros, en el mar y al pesado aire se mezclan, hinchan mi nariz y mis oídos. Pero el filo de mis orejas, empinándose, choca con los hedores y fragancias de que te hablo, y se transparenta; siente aquí una mezcolanza del morir y del amanecer, de lo que 
hierve y salpica, de lo que se cuece y se vuelve ácido, del apaciguarse por la fuerza o a pulso. Todo este fermento está y lo sé desde las puntas de mis orejas. Y veo, veo; puedo también, como tú, ser lo que sea. (62-63)

La apreciación que hace el zorro-narrador combina violentamente elementos que aparecen como opuestos; estos forman parte de la transgresiva heterogeneidad del puerto. La mezcla cultural, étnica y social, alterada por las condiciones económicas del acelerado Chimbote del período de la anchoveta, confronta elementos del entorno a la manera de un Eros y Thanatos de la existencia misma. Representada como explosión incontenible, la diversidad escapa a cualquier posibilidad de control, tanto del contexto del relato como del lenguaje en que este se plasma, produciendo una humanidad sumamente heterogénea, dentro de la que se puede "ser lo que sea". El zorro enunciador percibe fragancias y olores, y repara en sensaciones y estados opuestos que son, como ha señalado Lienhard, transitorios e inconclusos ("La última novela" 195). La muerte, situada textualmente al lado del amanecer, sugiere movimiento y no clausura, un estado con el que se convive permanentemente, y que no resulta ajeno a la cosmovisión andina. Algunos datos sobre el significado de la muerte en el mundo andino son registrados por Arguedas en un artículo publicado en el diario La Prensa de Buenos Aires, el 28 de enero de 1945, al mencionar las creencias indígenas y el consecuente sincretismo que se dio con la religión católica: "El indio está seguro de que la muerte es sólo el tránsito a otra vida; el catolicismo vino a confirmar esa antigua convicción; y ahora cree mucho más en la supervivencia del alma" ("La muerte" 394$) \cdot{ }^{18}$ En este sentido, sugiere el autor, la muerte para los andinos representaría una presencia cotidiana: "el encuentro con los muertos es tan fácil como ver a los vecinos" (394). Asimismo, en Dioses y hombres de Huarochirí, texto que Arguedas asumía como el mensaje casi incontaminado de la antigüedad ("Introducción" io) se reafirma esta cercanía con la muerte, al referir que cuando alguien moría quedaba como cadáver durante cinco días, y cumplido ese plazo "se desprendía su ánima “isio!”, diciendo, como si fuera una mosca pequeña” (II9). El texto registra también que al regreso de los muertos se los esperaba con ofrendas para celebrar su retorno. El muerto, feliz por el reencuentro, afirmaba "soy eterno, ya no moriré jamás" (II9). La idea de la muerte, en su doble faceta de convivencia y eternidad, se enfatiza a lo largo de los diarios y también en el texto ficcional. Por otro lado, inevitablemente encarna los espectros que permean el acto de la escritura y acechan a la persona del autor: "Un hombre relata la agonía que precede a su suicidio, que coincide y a veces se intercambia con la agonía de todo un pueblo" (Cornejo Polar, Los universos 
narrativos 263). La escritura incorpora la muerte como presencia constante en un Chimbote caótico, que por otro lado es contemplado como germen de una sustancia social en proceso de transformación. Se logra así la articulación, tan certeramente anunciada por Arguedas, entre la ficción, las reflexiones sobre el Perú, y el gesto suicida.

De allí que la escritura sea en la obra de Arguedas un arma que al mismo tiempo evoca la vida y enfrenta la muerte, posponiéndola, aunque sea de manera temporal. Según Eduardo Chirinos, la confrontación con la muerte en la novela es tan intensa como la lucha por el lenguaje como manifestación esencial de la vida: "La apuesta por un lenguaje utópico 'cargado' de pensamiento mítico que no tema apelar al ánima vital de la naturaleza, y que a la vez sea capaz de poner en escena la amalgama de frustraciones, miedos y deseos que nos configuran como seres sociales" (94). Cada personaje de El zorro se revela como parte de una humanidad doliente que, en medio de visiones de muerte y consciente de su propia vulnerabilidad, continúa, como el propio autor, en tanto le es posible, en la lucha por la vida. Esta terca batalla es encarnada en el relato principalmente por el personaje de Esteban de la Cruz, quien sufre una enfermedad que lo hace roncar y toser de forma continua, adquirida durante sus años de trabajo en las minas, antes de migrar a Chimbote. Su esperanza se cifra en que sus escupitajos no muestren sangre, sino una sustancia oscura parecida al carbón, que, de acuerdo a lo que le han informado, debe llegar a pesar cinco onzas para poder salvarlo de la muerte. El relato revela que la enfermedad, en lugar de restarle fuerzas, "le daba coraje" (Arguedas, El zorro 156). Esteban se muestra obsesionado con escupir carbón, ya que en ello radica su posibilidad de continuar viviendo, pero también se ve confrontado con la realidad: todos los que han sufrido la enfermedad han fallecido. Su amigo, el "zambo" Moncada, quien "habla la verdad que dicen los locos" (66) llega a la conclusión de que el mal de Esteban se debe a la introducción del capital foráneo y la explotación: "La muerte en Perú patria es extranjero" (I65). Más adelante, Esteban vuelca su rabia y su frustración: "la ira, la fuerza que tenía él, el mismo Esteban, contra la muerte, muy claramente contra la muerte, su juramento de vencerla, se alimentaba mejor del tono, la teniebla-lumbre, como él decía, de las predicaciones del profeta" (I69). Cuando Jesusa le sugiere a Esteban confesarse, este se niega, y Moncada manifiesta que su compadre "[n]o va preparar su muerte ni a confesión ni a canto desabrido que ni vida es, ni oración, sal ni pimienta ... Hay que caminar firme cuando hay pelea con la carcancha, igual que don Esteban, caminar, con su lirio negro desangrado en mi pecho, corazón" (179-I80). La férrea voluntad de Esteban de continuar viviendo se descubre cuando, pese a su evidente deterioro físico, 
ordena a su cuerpo continuar moviéndose. Finalmente, Moncada sugiere el advenimiento de la muerte, dejando entrever a la vez temor y esperanza: "Lirio de la muerte-vida que nadies apaga ... ¡Ya compadre, Esteban de la Cruz! Arriba la salvación. Mundo sin Moncada y sin su compadre" (200). El lirio negro que, como el vómito oscuro que sale del pecho de Esteban, se desangra también en el de Moncada, simboliza esa muerte presente evocada en el diario paralelo de Arguedas en la figura de la flor que crece en los campos de la sierra: "Esa flor afelpada donde el cuerpo de los moscones negrísimos, los hayronqos, se empolva de amarillo y permanece más negro y acerado que sobre los lirios blancos ... en mi pueblo, a esa flor le llaman ayaq sapatillan (zapatilla de muerto) y representa el cadáver" (24-25). El tema del moscardón hayronqo ha sido examinado por William Rowe, quien afirma que la muerte tendría en El zorro un signo al mismo tiempo positivo y negativo, y que la penetración del insecto en la flor

unifica el erotismo y la muerte. Al abrazar el polen amarillo de la flor, el insecto produce en el autor del Diario un efecto de pesadez la que significa "una explosión de la vida", explosión nuevamente asociada con la muerte porque implica la destrucción de la cascada dura metálica pero frágil. Para el autor, se trata de un conflicto irresoluble, entre "muerte deseada" y "muerte temida", que en cierto nivel podemos interpretar como el asumir la muerte como condición riesgosa de cambio. (II9)

El simbolismo de la flor conecta las luchas del autor y del personaje, y la resistencia tenaz de ambos a ser vencidos por la muerte. Además, la vinculación sugerida entre palabra y esputo, lenguaje y enfermedad (Portugal 450) da cuenta de las herramientas - por momentos precarias y finalmente insuficientes - para enfrentar la muerte. De manera similar a Esteban, quien expulsa por la boca el carbón salvador para poder continuar viviendo, el narrador enuncia historias con la misma finalidad: "Porque yo si no escribo y publico, me pego un tiro" (2I). Ambos sujetos el escritor en la vida real y el personaje ficcional - performan, en tanto es posible extender el proceso escritural, el rito de tránsito hacia esa muerte presente que se teme y a la vez se abraza.

Entre otras visiones que impregnan el trabajo final de Arguedas destaca una representación que resulta singular y esclarecedora del sentido trascendental de la muerte en la novela: el pasaje en el que el "zambo" Moncada llega a la plaza del mercado, descalzo y disfrazado de pescador, portando una cruz de madera. La forma en que se monta un "escenario", describiendo detalladamente el ambiente del mercado "cerca de los puestos de ropa, de verduras y mil chucherías que cubrían 
más de la mitad de la calle" (65) - y la aparatosa manera en que Moncada aparece y luego actúa, permiten al lector percibir y recrear la escena como un acto teatral, que correspondería, como se ha señalado, a un nivel de performatividad diferente al de la actuación de los zorros, narradores orales de la historia. Frente a un grupo de espectadores, el personaje saca un muñeco vestido exactamente como él, que cuelga del madero, para iniciar un monólogo dirigido a sí mismo y también a los demás:

Pobre Moncada, loco Moncada, todos te calumnian ... El gobierno te calumnia, te hace sudar, flagelar, calafatear con candela, te mete en los podridos del barro, del zancudo ... ¡El sol sabe quién soy yo, de mí quedará memoria! Braschi me odia; él tiene quijada de monogrande, de monazo grande. Oigan: Braschi ha hecho crecer este puerto; lo ha empreñado a la mar, ustedes son hijos de Braschi, ese Caín al revés, hermanos ... (67)

Resulta clara la denuncia de la pobreza, la opresión y la entrega del puerto al capital que hace el personaje, en armonía con la línea de pensamiento de Arguedas, quien perseguía "la liberación total de los pueblos tanto en cuanto a sus condiciones de existencia como en lo relacionado con el reconocimiento de sus tradiciones, legados y concepción del mundo" (Moraña i69). Asimismo, las frases de Moncada insinúan su aspiración a pervivir en el imaginario social, al exclamar que de él quedará memoria. Las palabras del loco - quien, como se ha mencionado, tendría la facultad de decir la verdad - descubren así un espacio de trascendencia que enlaza la idea de inmortalidad con la verdad que emana de su visión crítica de la realidad circundante, que coincide con la del autor. Este espacio en el que convergen verdad, inmortalidad y trascendencia se irá configurando progresivamente a lo largo de la obra ficcional.

Más adelante, Moncada recorre un largo camino hasta llegar a la estación del tren donde recoge los restos de un gallo que acaba de ser triturado por el vagón de la locomotora. Luego de anunciar, "Yo, loco, negro, pescador pescado, voy a alimentarme de esta sangre del gallo de la pasión" (Arguedas, El zorro 73), come la carne y bebe la sangre del gallo. Seguidamente observa el "fuego a muerte" en los ojos del moribundo Esteban de la Cruz y pasa a pronunciar otro discurso, al que da fin exclamando: "Yo era el gallo cansao, amigos. ¡Kikiriki! Ya resucité. jJa, ja, ja! Otro poquito y jadiós!" (73). La muerte, pasión y resurección, que forman parte del relato fundamental de la tradición cristiana, aparecen aquí como burda representación nacida de una mezcla cultural en la que conviven sujetos pauperizados y degradados, pero que constituye sobre todo una afirmación identitaria que incorpora y a la vez cuestiona la visión 
occidental del mundo. En relación a la inserción de elementos religiosos, Moraña ha señalado la sugerencia de los críticos sobre un paralelismo con motivos bíblicos en la obra de Arguedas, posiblemente a partir de la influencia del sacerdote Gustavo Gutiérrez (con quien Arguedas tenía una gran amistad) y su "Teología de la Liberación" (167). Además, menciona la estudiosa, se ha postulado que la novela Todas las sangres (1964) constituiría una alegoría bíblica en la que el personaje Rendón Willka representaría a Cristo, encarnando "nuevas formas de conciencia social principalmente a través de la búsqueda de una opción progresista capaz de superar la estructura social arcaica resistiendo al mismo tiempo los efectos devastadores de la modernización" (I68). En El zorro el personaje del loco Moncada, a través de su sacrílega parodia de la muerte y resurección, establece una ruptura con la narrativa anterior de Arguedas, cancelando el proyecto de progreso; la búsqueda de opciones más estructuradas se diluye frente al caos deshumanizante del contexto. Como lo indica Moraña:

el personaje de "el loco Moncada" pone ... en juego otros elementos por los cuales se cuela una percepción diferente, subversiva y dislocada, de la realidad circundante. A través de un discurso fracturado que deconstruye la racionalidad del capitalismo hirviente de Chimbote y por medio de sus atrabiliarias acciones y de sus disfraces, Moncada subvierte la lógica de la explotación y el disciplinamiento del trabajo reproductor del capital con la improductividad lúdica de una percepción turbulenta e indisciplinada de su entorno. Su presencia perturbadora y excéntrica se resiste a la asimilación total y simboliza el mundo amenazado por la alternatividad epistémica y la heteroglosia, cualidades que descomponen el mundo en fragmentos sin relación ni significado. (I6I)

A través de sus alucinados pero certeros discursos, el personaje de Moncada estaría incorporando la voz de Arguedas, no solo en términos de la denuncia que plantea sobre la realidad opresiva del Perú, sino también en sus manifestaciones sobre la muerte, que permiten entrever la proyección del suicidio en la obra. Después de la impresionante escena del gallo, Moncada, siempre llevando la cruz, continúa su camino, para encontrarse con que el cementario ha sido amurallado. El camposanto representa un lugar de división entre ricos y pobres: los muertos ricos en la parte baja, y los pobres, sus lugares de entierro señalados con endebles cruces de madera, en lo alto del cerro. La novela aclara que los pobladores de las "barriadas" (asentamientos humanos periféricos) ya habían recibido una notificación de las autoridades ordenándoles enterrar a sus muertos en una pampa destinada a ser el camposanto de los pobres, sin haber sido informados sobre el destino de los cuerpos ya sepultados. Cuando 
Moncada llega, observa a los pobres arrancar las cruces de madera para llevarlas al terreno donde deben trasladar su cementerio. La oposición entre culturas, la de los andinos o mestizos pobres, y la de los criollos o acriollados más acomodados del puerto, se visualiza en el espacio fisico de la muerte, que resulta también caótico en su descripción de las cruces clavadas en desorden en la cima del cerro, en contraste con los nichos de cemento ordenadamente dispuestos en la parte baja. La organización territorial es relevante en relación a lo afirmado por Lienhard sobre la inserción de las raíces andinas en los límites espaciales que impone el relato, en particular, el mundo dualista con sus partes de arriba y abajo (Cultura andina IO2). La escena adquiere una fuerza singular a partir de la acción de los pobladores, quienes terminan de retirar las cruces de sus muertos y las llevan consigo, en una procesión, que como "un gusano negro" (Arguedas, El zorro 80), debe atravesar "casi todo el médano de San Pedro, donde los antiguos yungas construyeron el adoratorio ahora menos conocido, más grande y señor de la arena" (8I). La caminata resulta larga y difícil, y es observada con desconfianza por los pobladores de las áreas que atraviesan antes de llegar al páramo, lugar donde finalmente se reinsertan las cruces desprovistas de cuerpos. El episodio culmina así con una imagen de desolación que deviene, gracias al espíritu comunal, en acto de resistencia a la modernidad y a la marginación que plantea la nueva forma física del antiguo cementerio. El espacio de la muerte se reconstruye ideológica y materialmente con elementos andinos cercanos al paraje donde los pobladores fundan el camposanto - el adoratorio de los antiguos yungas - dotándolo de nuevas significaciones, como se constata en el emotivo discurso del delegado Gregorio Balazar:

Conciudadanos que cargáis las cruces de vuestros muertos ... aquí hemos llegado, en nombre del Padre, del Hijo, del Monicipio y del Subprefecto, pues. ¡A enterrar los cruces que estamos trayendo, fúnebres! En cualquier partecita. Aquí estamos en la hondonada. Aquí nadies nos va a encontrar para que nos llevan al valle de Josafat. De a siempre nos quedamos. A nadies nos ha enteresado, valgan verdades, que cada quién conoce donde, el punto donde, para el eterno, queda el muerto padre, hermano, hermana. Lo que hay en el corazón es el campo donde tranquilo está el muerto, acompañando a su comunidad pueblo. (83)

Frente a la afrenta sufrida por los familiares de los muertos, que se asienta en la diferencia étnica, social y cultural, el delegado llama a los dolientes a una digna resignación. Al mismo tiempo, el discurso de Balazar subvierte la tradición occidental y cristiana cuando frente al dolor de ser expulsados y despojados de los restos de sus seres queridos, cuestiona tanto el 
progreso que supuestamente implicaría la reforma del cementerio como el desenlace asumido por el cristianismo para la humanidad - la reunión en el valle de Josafat a la hora del Juicio Final - para, de manera alternativa, optar por la muerte andina con la que se convive a diario. Ahondando en la narrativa de Arguedas como portadora de propuestas que desafían visiones pre-establecidas, William Rowe ha enfatizado la subversión que encarnan las formas andinas de representación frente a las prácticas de la cultura dominante: "los cambios que generan cuando son utilizadas de manera innovadora y no nostálgica significan una transformación literariasocial no menos profunda que la que introdujo la burguesía en su tiempo (Ensayos arguedianos 135). Esta reflexión ilumina el rol de Moncada como un Cristo enloquecido que marcha hacia el sacrificio, emulado por la procesión de dolientes, y su subversión de los elementos cristianos para sugerir un espacio propio - andino - desde el que se interpela la dominación y la muerte. En este sentido, tanto la performance de Moncada, quien se redime como personaje en función a la verdad de la que es portador, como la creación por los pobres de un cementerio sin cuerpos, desafían creativamente los usos y creencias occidentales.

Asimismo, la desvalidez de la procesión de cruces y la nueva ubicación en un terreno alejado y casi inaccesible ponen en evidencia la ausencia de la materialidad de los cuerpos. Ello tiene como efecto una disgregación de la muerte en materia y espíritu, produciéndose una ruptura en el tiempo del relato, que se resuelve en el espacio eterno de la memoria colectiva. Cobran así un sentido específico el recorrido de las cruces, la alusión al "gusano" de familiares que se desplaza como masa humana compacta y la "comunidad pueblo," porque dan vida a una colectividad andina que porta en su corazón a los muertos despojados de su materialidad corpórea. Paralelamente el diario, parte del cual debía leerse en público durante su funeral según las indicaciones del autor, propone también una ruptura temporal - el fin de un ciclo y la apertura de otro - y alienta al narratario colectivo - los lectores futuros - a que "despidan en mí a un tiempo del Perú cuyas raíces estarán siempre chupando jugo de la tierra para alimentar a los que viven en nuestra patria" (Arguedas, El zorro 288). La finitud de la materia y la inmortalidad de la memoria se enfrentan en la obra, confrontación de la que el espíritu andino resulta vencedor, consolidándose un espacio textual de verdad y trascendencia que termina por derrotar a la muerte.

Es en este espacio de eternidad, verdad y trascendencia en el que Arguedas se instala a partir del proceso de escritura y de su propia muerte como performance. En la obra póstuma, los zorros danzan performando la muerte, el loco Moncada protagoniza un sinfín de roles al enunciar su 
verdad, los personajes se enfilan hacia sus anunciados finales, mientras el autor prepara el acto final que lo llevará a la inmortalidad. Las representaciones textuales, tanto en la obra factual como en la ficcional, permiten apreciar la forma en que el sentimiento de enfrentamiento y fascinación con la muerte se va desplazando desde la decisión de morir, recurrentemente presente en los diarios y las cartas, hasta la decisión de trascender que se proyecta en la obra. La voz de Arguedas, transmutada en la del loco Moncada que apela a la inmortalidad, anuncia a ese lector futuro su posibilidad de pervivir en la memoria colectiva, reafirmándose como autor y sujeto andino. Asimismo, la inscripción del suicidio en los documentos factuales (diarios, cartas) se actualiza en la sustancia textual de la ficción, construyendo, en la convivencia de vida y muerte, un lugar alternativo en el que esta última adquiere un matiz positivo, refugio que Arguedas crea desde la concepción andina de la muerte. En tanto acto de performance dirigido a una audiencia que ha de leer su obra bajo el signo del suicidio, la muerte por mano propia proviene del texto y retorna a este, descubriendo la voluntad del autor de ir más allá de la muerte física y dejar un legado para la posteridad, herencia que puede contemplarse considerando su prolongada lucha por inscribir su persona y su obra como representativas de lo andino. Como lo ha sugerido Braud, el suicidio y la escritura autobiográfica, en este caso fuertemente enlazada con el relato ficcional, brindan al autor la posibilidad de recuperar una identidad (andina) amenazada: "l'image finale que l'auteur donne de lui, notamment, repose sur cette attente de reconaissance; elle le réintègre parmi les vivants, le réinstalle dans le jeu des rapports sociaux, lui redonne une identité un temps menacée" (30). Aun cuando la muerte se revela como única posibilidad en el contexto caótico de El zorro y el suicidio cancela la vida material del autor, las performances reales y ficcionales, al entrelazar verdad, vida y muerte, sugieren la derrota de esta última frente a la trascendencia del ser, gracias a la cual autor y obra emergen intactos, otorgando un nuevo sentido tanto a la experiencia vivencial como a la escritura.

Mount Royal University

NOTAS

I El cuestionamiento de la escritura de Arguedas es evidente en la "displicencia, que a veces llega al desplante" referida por Antonio Cornejo Polar en relación a la omisión de la obra de Arguedas de importantes estudios sobre literatura 
latinoamericana, así como a la crítica a su expresión narrativa ("José María Arguedas" 2II-2I2). Asimismo, es sabido que el reconocimiento de la autenticidad del referente en los textos literarios de Arguedas constituyó un tema espinoso y polémico durante la vida del escritor e incluso después de fallecido, no obstante su reconocida importancia. Un espacio puntual de la crítica a la narrativa de corte indigenista de Arguedas se sitúa en la mesa redonda "Todas las sangres", realizada el 23 de junio de 1965 , que puso en tela de juicio la validez, en tanto reflejo de la realidad, de sus representaciones del universo andino. Dorian Espezúa ha demostrado que el debate se centró en la evaluación de la novela como si se tratara de un documento que refleja fielmente la realidad peruana, lo que arrojó como conclusión que "la novela no servía como un documento sociológico ni como testimonio válido de la realidad peruana" (Todas las sangres 303). Según el crítico, la mesa redonda habría dejado de lado una lectura acuciosa desde una perspectiva literaria (306).

2 De esta indiferente, muchas veces peyorativa, visión de su obra, el autor indigenista dio vívida cuenta. Antonio Cornejo Polar comenta que esta incomprensión se debía a que "una doble y contradictoria solicitación obsede a Arguedas desde el comienzo mismo de su producción literaria: la de ser radicalmente fiel al universo que asume como propio y representa en sus obras ('yo lo tengo que escribir tal cual es, porque yo lo he gozado, yo lo he sufrido') y la de resultar inteligible para sus lectores, en general hablantes de otro mundo ..." (“José María Arguedas, revelador" 2II).

3 Tomás Escajadillo menciona la aparición en 1973 de los tres primeros libros "serios" sobre Arguedas, los de Sara Castro Klarén, Antonio Cornejo Polar y Gladys Marín ("Pasó el tiempo" 76). En este mismo sentido, José Alberto Portugal subraya el trabajo de cinco críticos: Antonio Cornejo Polar, Sara Castro-Klarén, Gladys Marín, Angel Rama y William Rowe en lo que explica como una "nueva atención sobre el autor y su obra, el inicio, en realidad de todo un nuevo proceso de significación" (Las novelas 27).

4 Como lo menciona Dorian Espezúa, sería erróneo intentar una lectura que analice la obra de Arguedas únicamente desde lo ficcional, o desde lo no ficcional, o lo autobiográfico o testimonial (Todas las sangres 303-304), ya que estos aspectos se imbrican en su obra, en particular en El zorro de arriba y el zorro de abajo.

5 Por ejemplo, Jean Franco sostenía que las dificultades de Arguedas para plasmar la realidad de Chimbote en El zorro, se deben a que "cuando se puso a escribir El zorro, las comunidades serranas en que había basado su visión utópica ya estaban mermadas por la emigración a la costa. La cultura tradicional, fuente para él de ciertos valores más humanos que los del capitalismo, estaba prostituida por contacto con los valores de un capitalismo 
crudo y primitivo. El éxodo de la sierra y la destrucción de las comunidades afectó profundamente a Arguedas como persona y como escritor. Le era imposible plasmar las formas de esta nueva realidad" ("Modernización, resistencia y revolución" 5). Por su parte, Annette Rubado hace referencia a la respuestas generadas en la crítica ante la publicación de El zorro: “Los zorros in particular has engendered acute affective responses in which critics read the novel as a utopia that performs a pachacuti (a turning over of the world), or equally polarizing, as a dystopia in which the author's suicide, by pervading the texts, confirms the impossibility and failure of the attempts to make meaning of dispossession" ("Dancing Death" 322).

6 El Primer Diario fue publicado en el número 6 de la revista Amaru en 1968, y partes de la novela y del Tercer Diario aparecieron en I969, en el número II de Amaru.

7 El cortejo fúnebre y el entierro de José María Arguedas constituyeron un gran evento público, en el que, siguiendo los deseos del autor, se incluyeron performances artísticas: “El violinista Máximo Damián Huamani, de San Diego de Ishua, Lucanas, y los músicos Jaime Guardia, Alejandro Vivanco y los hermanos Chiara acompañaron el cortejo fúnebre tocando, con arpas, quenas y charangos, la Agonía de la Danza de las tijeras, mientras dos de esos danzantes indios, que habían fascinado a Arguedas desde niño, iban bailando junto al ataúd vestidos con sus multicolores trajes de plumas y espejos" (Vargas Llosa, La utopía i3).

8 La definición de "performance" deriva del verbo "to perform", que denotaría la capacidad de ejecutar de manera efectiva una acción o, en un contexto artístico, por ejemplo, desempeñar un rol teatral, danzar, o tocar un instrumento musical. Una performance puede tener lugar en el "mundo real" o mostrar eventos ficcionales (Berns 95-96).

9 El uso del término "veridicción" en el contexto de la crítica literaria hispanoamericana se vincula principalmente a los géneros autobiográfico y/o testimonial. El término subraya la pretensión de verdad de determinados discursos. En este sentido, se ha enfatizado la vinculación del término con "los procedimientos lingüísticos-sociales que sostienen la 'aspiración' de un discurso a ser un discurso verdadero" (Renato Prada Oropeza cit. en SarfatiArnaud 422).

Io Como se sabe, José María Arguedas intentó suicidarse por primera vez en 1966.

1I Con excepción de la novela El sexto, que surge de su experiencia en la prisión en Lima que lleva ese nombre.

I2 El personaje de Esteban de la Cruz existió en la vida real. La entrevista que sostuvo con Arguedas fue publicada por Wilfredo Kapsoli ("Coloquio de zorros" I46-I6I). 
13 En este contexto, es importante anotar el temprano reconocimiento hecho por Mario Vargas Llosa de la autenticidad en la representación de los indios por Arguedas. En un artículo publicado en 1969, Vargas Llosa afirmaba que Arguedas "no intenta fotografiar al mundo andino (que él conoce perfectamente): quiere instalar al lector en su intimidad. Los indios abstractos del indigenismo se convierten en Arguedas en seres reales, gracias a un estilo que reconstituye en español y dentro de perspectivas occidentales, las intuiciones y devociones más entrañables del mundo quechua, sus raíces mágicas, su animismo colectivo, la filosofía entre resignada y heroica que le ha dado fuerzas para sobrevivir a siglos de injusticia" ("Novela primitiva" 32 ). Cabe señalar que este artículo salió a la luz antes de la publicacion de la obra póstuma de Arguedas.

14 Julio Ortega da cuenta de la complejidad de los diálogos insertos en El zorro: "este es un diálogo no siempre razonado, no necesariamente obligado a los turnos del hablante y el oyente; sino un diálogo de distinto protocolo. Hecho a partir de sobreentendidos, está fragmentado entre retazos de un discurso oblicuo y sin centro. De manera que las palabras no buscan sólo representar el mundo que refieren, los hablantes no intentan sólo intercambiar información, y la oralidad no pretende sólo reproducir el instante enunciado ... En buena cuenta, no sabremos necesariamente más del fenómeno pesquero o de la situación social o política de Chimbote a través de estos diálogos.

Conoceremos, en cambio, distintas e intrincadas interpretaciones de ese fenómeno y esa situación; versiones que refractan el mundo en el habla, como su inversión subjetiva, ambigua y sospechosa" ("Los zorros de Arguedas" 273).

15 Los zorros de "arriba" y de "abajo" hacen referencia a la oposición sierra/costa (Cornejo Polar, Los universos narrativos 297; Lienhard, "La última novela" I93). En relación a Dioses y hombres de Huarochirí, Lienhard anota que "el 'arriba' y el 'abajo' de los dos zorros se refiere a la parte alta y a la parte baja de una zona que corresponde más o menos a la actual provincia de Huarochirí” ("La última novela" I93).

16 De acuerdo a la nota de Angel Rama al inicio de la edición de Dioses y hombres de Huarochirí, publicada por Siglo Veintiuno en 1975, el manuscrito fue recogido a fines del siglo XVI en la provincia de Huarochirí por el sacerdote cuzqueño Francisco de Ávila y se conservó en la Biblioteca Nacional de Madrid. Su edición completa fue lograda por el Museo Nacional de Historia y el Instituto de Estudios Peruanos, en Lima en 1966, junto a la traducción al español a cargo de José María Arguedas (7).

I7 Con respecto al posible lector de El zorro, Lienhard afirma que la dinámica de la novela propone un "lector interno" que tendría la capacidad de deconstruir los códigos occidentales e indígenas que componen el relato. Pensado para un futuro, este lector provendría de los estratos más cultos de los sectores 
populares forjados en la migración masiva de los andinos a las ciudades de la costa ( "La última novela" 2I4). El fenómeno de la migración andina a las ciudades, representado en la última novela de Arguedas, ha sido estudiado por José Matos Mar quien afirma que "la respuesta de los sectores populares a esta inmensa diversidad de estímulos culturales no es mecánica sino creativa. Las migraciones han logrado traer a las ciudades elementos culturales y sociales de sus lugares de origen, incluido el idioma, que se expresa de muy variadas formas" (Desborde popular 51).

18 Agradezco a Gabriela Falconí Piedra por la ayuda generosamente prestada en la búsqueda de fuentes para este artículo, particularmente en relación a la cosmovisión andina de la muerte.

OBRAS CITADAS

A Nó n I M o. Dioses y hombres de Huarochirí. México: Siglo Veintiuno, 1975.

A RGUEDAS, JosÉ ma Ría. “Introducción”. Anónimo. Dioses y hombres de Huarochirí.

México: Siglo Veintiuno, I975. IO-I8.

—. “'Luz negra, compadre. ¡Levántese!”. Amaru ir (I969): 3-II.

-. "La muerte y los funerales". Arguedas, José María. Obra Antropológica.Tomo I. Lima: Editorial Horizonte, 20I2. 394-397.

-. "El zorro de arriba y el zorro de abajo". Amaru 6 (1968): 42-49.

-. El zorro de arriba y el zorro de abajo. Buenos Aires: Editorial Losada, I97I.

BERNS, U TE. "The concept of Performativity in Narratology". European Journal of English Studies I3.I (2009): 93-I08.

BRAUD, M I C H L L. La tentation du suicide dans les écrits autobiographiques 1930-1970. París: Presses Universitaries de France, 1992.

CORNEJ O POLAR, ANT ONio. "José María Arguedas: revelador de una realidad cambiante”. Novela Iberoamericana Contemporánea. Cuadernos de Literatura de la Emancipación Hispanoamericana y Otros Ensayos. Segunda sesión del XV Congreso del Instituto de Literatura Iberoamericana. Lima: Universidad Nacional Mayor de San Marcos, I97I. 2II-2I6.

-. Los universos narrativos de José María Arguedas. Buenos Aires: Editorial Losada, I973.

CORNEJO POLAR, ANTONIO, ANTONIO ESCOBAR, MARTIN LIENHARD Y WILLIAM Row E. Vigencia y universalidad de José María Arguedas. Lima: Editorial Horizonte, 1984.

CHIRINOS, EDUARDO. Nueve miradas sin dueño. Ensayos sobre la modernidad y sus representaciones en la poesía hispanoamericana y española. Lima: Fondo de Cultura Económica/Pontificia Universidad Católica del Perú, 2004.

E sca ja di l Lo, t o más. "Pasó el tiempo de las elegías". José María Arguedas, veinte años después: huellas y horizonte. 1969-1989. Comp. Rodrigo Montoya. Lima: 
Escuela de Antropología, Facultad de Ciencias Sociales, Universidad Nacional Mayor de San Marcos, I991. 75-82.

E SP EZÚA, D O R A N. Todas las sangres en debate. Científicos sociales versus críticos literarios. Lima: Magreb, 20 II.

FRANCO, JEAN. “Modernización, resistencia y revolución. La producción literaria de los años sesenta". Escritura. Teoría y Crítica Literarias 2.3 (1977): 3-19.

G U T A RRA, RAM IRO. "El suicidio en El zorro de arriba y el zorro de abajo". Zorros al

fin del milenio. Ed. Wilfredo Kapsoli. Lima: Universidad Ricardo Palma, 2004.

KAPSOLI, W I LFRED 0. "Coloquio de zorros. José María Arguedas conversa con

Esteban de la Cruz e Hilario Mamani”. Zorros al fin del milenio. Ed. Wilfredo

Kapsoli. Lima: Universidad Ricardo Palma, 2004.

LIENHARD, MARTIN. Cultura andina y forma novelesca. Zorros y danzantes en la última novela de Arguedas. Lima: Editorial Horizonte, I990.

—. "La última novela de Arguedas: imagen de un lector futuro". Zorros al fin del milenio. Ed. Wilfredo Kapsoli. Lima: Universidad Ricardo Palma, 2004.

MARÍ N, G L A DYS. La experiencia americana de José María Arguedas. Buenos Aires: Fernando García Cambeiro, I973.

matos mar, José. Desborde popular y crisis del Estado. Veinte años después. Lima: Fondo Editorial del Congreso del Perú, 2005.

m orañ A, ma Bel. Arguedas/Vargas Llosa. Dilemas y ensamblajes. Madrid:

Iberoamericana, 2013 .

murRa, JoH y mercedes ló pez-BARAlt, Eds. Las cartas de Arguedas. Lima:

Pontificia Universidad Católica del Perú, 1996.

o' H AR A, E D G A R, E D. Cartas de José María Arguedas a Pedro Lastra. Santiago de Chile: LOM Ediciones, 1997.

ORTEGA, JU L I o. "Los zorros de Arguedas: migraciones y fundaciones de la modernidad andina". Ed. Wilfredo Kapsoli. Zorros al fin del milenio. Lima: Universidad Ricardo Palma, 2004. 259-28I.

o R T IZ, Al EJ AN D R o. José María Arguedas. Recuerdos de una amistad. Lima: Pontificia Universidad Católica del Perú, 1996.

P O R T U A L, Jo SÉ A L B E R T o. Las novelas de José María Arguedas. Una incursión en lo inarticulado. Lima: Pontificia Universidad Católica del Perú, 2007.

RAMA, ÁNGEL. "Nota a la presente edición". Anónimo. Dioses y hombres de Huarochirí. México: Siglo Veintiuno, 1975· 7-8.

RoWE, William. Ensayos arguedianos. Lima: Centro de Producción Editorial de la Universidad Nacional Mayor de San Marcos/Sur Casa de Estudios del Socialismo, 1996.

Rubado, An net te. "Dancing Death: Performing Dispossession in Arguedas". $M L N$ Hispanic Issue I27.2 (2OI2): 318-34O.

SARFATI ARNAUD, MONIQUE. "El discurso testimonial latinoamericano como expresión de una paradoja”. Comp. Monique Carcaud-Macaire. Questionnement 
des formes, Questionnement du sens. Montpellier: Éditions du CERS, I997• 4I3422.

VARGAS Llos A, MARIO. “Novela primitiva y novela de creación en América Latina”. Revista de la Universidad de México - UNAM Iо (1969): 29-36.

- La utopía arcaica. José María Arguedas y las ficciones del indigenismo. México: Fondo de Cultura Económica, I997. 